\title{
BMJ Open Effectiveness of the Assessment of Burden of COPD (ABC) tool on health-related quality of life in patients with COPD: a cluster randomised controlled trial in primary and hospital care
}

To cite: Slok AHM, Kotz D, van Breukelen $\mathrm{G}$, et al. Effectiveness of the Assessment of Burden of COPD (ABC) tool on health-related quality of life in patients with COPD: a cluster randomised controlled trial in primary and hospital care. BMJ Open 2016;6:e011519. doi:10.1136/bmjopen-2016011519

- Prepublication history and additional material is available. To view please visit the journal (http://dx.doi.org/ 10.1136/bmjopen-2016011519).

Received 15 February 2016 Revised 25 May 2016 Accepted 26 May 2016

CrossMark

For numbered affiliations see end of article.

Correspondence to Annerika HM Slok; annerika. slok@maastrichtuniversity.nl

\section{ABSTRACT}

Objective: Assessing the effectiveness of the Assessment of Burden of COPD (ABC) tool on diseasespecific quality of life in patients with chronic obstructive pulmonary disease (COPD) measured with the St. George's Respiratory Questionnaire (SGRQ), compared with usual care.

Methods: A pragmatic cluster randomised controlled trial, in 39 Dutch primary care practices and 17 hospitals, with 357 patients with COPD ( postbronchodilator $\mathrm{FEV}_{1} / \mathrm{FVC}$ ratio $<0.7$ ) aged $\geq 40$ years, who could understand and read the Dutch language. Healthcare providers were randomly assigned to the intervention or control group. The intervention group applied the ABC tool, which consists of a short validated questionnaire assessing the experienced burden of COPD, objective COPD parameter (eg, lung function) and a treatment algorithm including a visual display and treatment advice. The control group provided usual care. Researchers were blinded to group allocation during analyses. Primary outcome was the number of patients with a clinically relevant improvement in SGRQ score between baseline and 18-month followup. Secondary outcomes were the COPD Assessment Test (CAT) and the Patient Assessment of Chronic IIIness Care (PACIC; a measurement of perceived quality of care).

Results: At 18-month follow-up, $34 \%$ of the 146 patients from 27 healthcare providers in the intervention group showed a clinically relevant improvement in the SGRQ, compared with $22 \%$ of the 148 patients from 29 healthcare providers in the control group (OR $1.85,95 \% \mathrm{Cl} 1.08$ to 3.16). No difference was found on the CAT $(-0.26$ points (scores ranging from 0 to 40 ); $95 \% \mathrm{Cl}-1.52$ to

\section{Strengths and limitations of this study}

- This study was a pragmatic study, which makes the results more applicable to daily care.

- The study was executed nationwide in primary and hospital care.

- Owing to the design of the study, no blinding and allocation concealment was possible.

- Owing to the pragmatic design, not all data were reported that were necessary to perform all analyses.

0.99). The PACIC showed a higher improvement in the intervention group ( 0.32 points (scores ranging from 1 to 5 ); $95 \% \mathrm{Cl} 0.14$ to 0.50 ).

Conclusions: This study showed that use of the $A B C$ tool may increase quality of life and perceived quality of care.

Trial registration number: NTR3788; Results.

\section{INTRODUCTION}

Chronic obstructive pulmonary disease (COPD) is a chronic disease with millions of sufferers worldwide. This number is expected to increase, mainly due to an ageing population and an increase in smoke exposure in women. ${ }^{1-3}$

COPD has a major impact on daily life and quality of life that goes beyond airway limitation. ${ }^{4-8}$ The Global Initiative for Chronic Obstructive Lung Disease (GOLD) guideline 
recommends a combined assessment of COPD using the so-called 'ABCD' classification model, which, apart from spirometry, assesses future risk (exacerbations) and current burden/impact of disease using questionnaire data. ${ }^{3}$ However, tools advocated to assess the burden of COPD only measure a limited number of aspects and do not provide a visual display to educate and involve patients in their treatment. Perhaps even more importantly, the way in which to make use of the patientreported outcomes or the impact of assessing the burden of disease in this way on outcomes of care has not been tested at all. Therefore, the Assessment of Burden of COPD (ABC) tool was developed, ${ }^{9}$ an innovative tool measuring and visualising integrated health status. An important part of the tool is the ABC scale (see online supplementary appendix A), which is largely based on the Clinical COPD Questionnaire (CCQ), ${ }^{10}$ and which measures the experienced burden of COPD. The CCQ was adapted by adding 4 questions to the existing 10 questions, to comply with the definition of burden of COPD, which was formulated by an expert team and confirmed by patients and healthcare providers. ${ }^{9}$ The ABC scale consists of five domains (ie, symptoms, functional state, mental state, emotions and fatigue $)^{9}$ and shows excellent reliability and validity. ${ }^{11}$ This scale is combined with other parameters (ie, lung function, exacerbations, body mass index, comorbidity, smoking status and self-reported level of physical activity) to assess the integrated health status of a patient with $\mathrm{COPD}$. The ABC tool visualises the outcome (using balloons, see figure 1) and therewith promotes awareness for patient and healthcare provider, and offers a treatment algorithm. Moreover, it provides the opportunity to support personalised care planning including a personal treatment goal. When a balloon is selected, an evidence-based treatment advice is shown, which the patient and healthcare provider can discuss. They can then decide on a treatment plan together through shared decision-making (see box 1).

The majority of treatment options include lifestyle changes, such as smoking cessation and increasing physical activity, which requires commitment, engagement and self-management skills of patients. ${ }^{12}{ }^{13}$ The ABC tool can be used as a communication tool in primary and hospital care (ie, in patients with mild/moderate and severe/very severe COPD), and it also provides the opportunity to monitor progression or deterioration by displaying the balloons of previous visits in grey (see figure 1). We hypothesised that giving patients the possibility and the responsibility in setting personal treatment goals and making their own treatment plan will influence self-management, facilitate and stimulate behavioural change, and eventually lead to an improved quality of life.

The primary aim of this study was to assess the effectiveness of using the $\mathrm{ABC}$ tool in patients with $\mathrm{COPD}$ on disease-specific quality of life based on the St. George's Respiratory Questionnaire (SGRQ), ${ }^{14}$ over a period of 18 months compared with a control group receiving usual care.

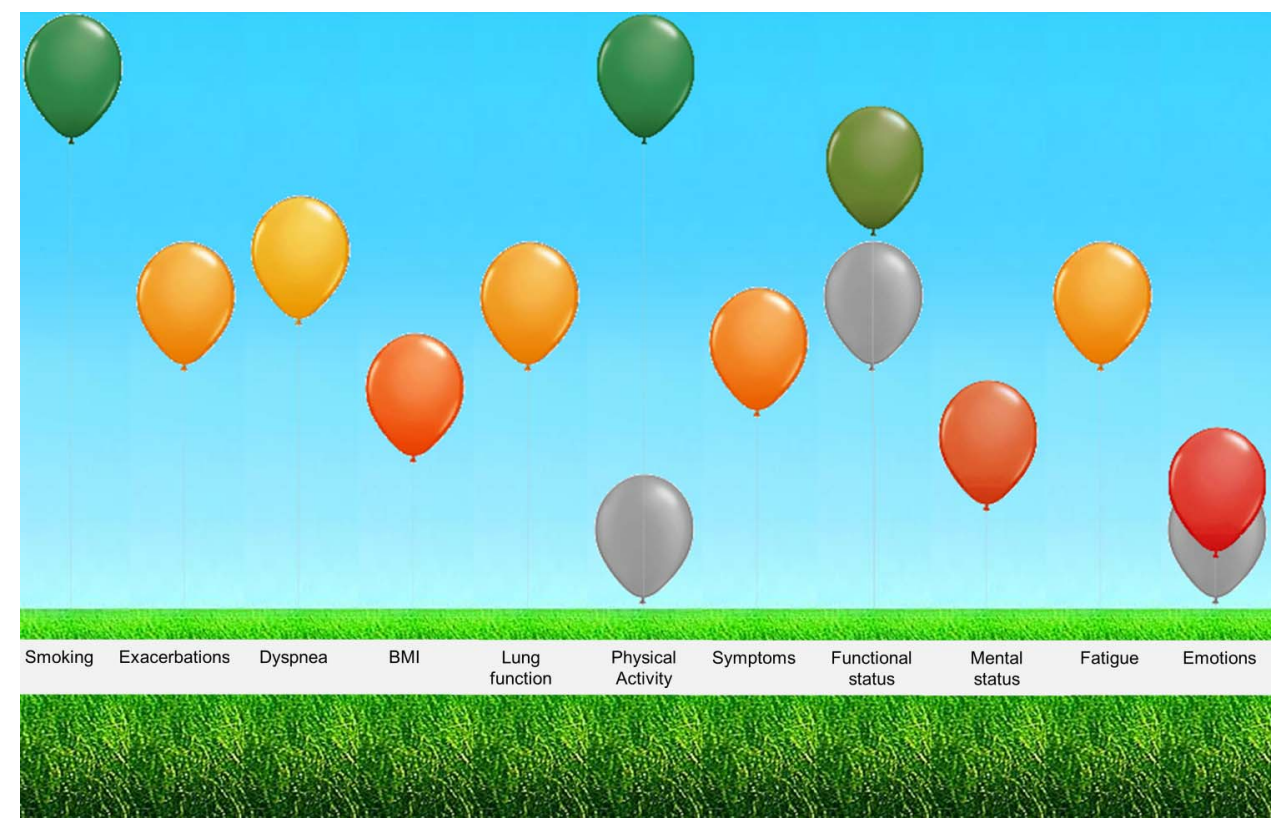

Figure 1 Visualisation of the integrated health status of a patient with COPD. The green balloons towards the top of the figure indicate a satisfactory score in that domain, whereas the red balloons signify a low score and orange balloons an intermediate score. Grey balloons are the balloons of previous visits which provide the opportunity to monitor over time. The five domains of experienced burden of COPD, as measured with the ABC scale, are represented by the last five balloons, symptoms, functional status, mental status, fatigue and emotions. Dyspnoea (evaluated by the Medical Research Council (MRC) scale ${ }^{18}$ ) and level of physical activity are also reported by the patients. Smoking status, exacerbations, body mass index (BMI) and lung function are reported by the healthcare providers. 
Box 1 Example of a patient's personal goal and treatment plan

\section{Patient Ms A}

This patient completed the Assessment of Burden of COPD (ABC) scale, the Medical Research Council (MRC) scale and reported her level of physical activity. Additional parameters were reported by the healthcare provider. The $A B C$ tool is shown in figure 1. The patient decides, together with the general practitioner (GP), to increase her level of physical activity.

Treatment plan:

Patient will raise her level of physical activity. Evaluation in 3 months.

Personal goal:

Walking my dog, three times a day, every day, for at least 15 min each time.

Secondary outcomes were quality of life based on the COPD Assessment Test (CAT) ${ }^{15}$ and the patients' perceived quality of care as assessed with the Patient Assessment of Chronic Illness Care (PACIC).$^{16}$

\section{METHODS}

\section{Study design, setting and patients}

The current study was a pragmatic, two-armed, cluster randomised controlled trial, conducted in 56 healthcare centres (39 primary care, 17 hospital care) across the Netherlands from March 2013 to May 2015 (Netherlands Trial Register, NTR3788). Ethics approval was obtained from the Medical Ethics Committee of Zuyderland Hospital, Heerlen, the Netherlands. A detailed protocol of this study has been published elsewhere. ${ }^{17}$ Informed consent was signed by patients prior to enrolment.

Healthcare providers were recruited by the researchers, with no specific criteria or prerequisites. These healthcare providers recruited patients, who were eligible to participate if they had a spirometry-confirmed diagnosis of COPD (postbronchodilator $\mathrm{FEV}_{1} / \mathrm{FVC}$ $<0.7$ ), were 40 years of age or over and could understand and read the Dutch language. Exclusion criteria were as follows: exacerbation $<6$ weeks before initiation of the study, an addiction to hard drugs, a life-threatening comorbid condition or pregnancy at the start of the study. ${ }^{17}$ Eligibility criteria were checked by the healthcare providers.

\section{Randomisation and masking}

We randomised at the level of healthcare providers to prevent contamination. Block randomisation of healthcare centres (random blocks of 2, 4 and 6), stratified by healthcare setting (ie, primary vs hospital care), was performed by the researchers using a computer program developed by the Maastricht University Centre for Data and Information Management (MEMIC). Blinding of healthcare professionals and patients was not possible due to the nature of the intervention, but the study team was blind to the nature of the treatment arms in the dataset. Unblinding was performed after unanimous agreement on data cleaning, handling of missing data, statistical analyses and conclusions drawn for the primary outcome.

\section{Intervention}

Healthcare providers (ie, general practitioners (GPs), practice nurses, pulmonologists and nurse specialists) were instructed to use the $\mathrm{ABC}$ tool during their routine consultations. As described in the study protocol, patients should visit their healthcare providers at least four times during the 18-month follow-up. ${ }^{17}$ Therefore, healthcare providers were instructed to invite patients for consultation at least once every 6 months. In each consultation, patients were asked to fill out the $\mathrm{ABC}$ scale ${ }^{9}$ report their dyspnoea using the Medical Research Council (MRC) dyspnoea scale ${ }^{18}$ and self-report their level of physical activity. Healthcare providers were instructed to obtain some additional parameters (ie, lung function, exacerbations, body mass index, comorbidity and smoking status) and enter these into the computer program. The program displayed the results as balloons (see figure 1 for an example). The colours and altitude of the balloons and corresponding implications could then be discussed, and consequently, patients and healthcare providers could decide on a treatment plan together. Patients were encouraged to formulate a personal treatment goal, in their own words, and a specific treatment plan in accordance with this goal (box 1 provides an example). It was possible to print out an overview of the balloons, the personal goal and the treatment plan at the end of the consultation. The ABC tool is also meant to be used to monitor patients' health status: previous results are displayed using grey balloons, resulting in the possibility to discuss progress and deterioration of different parameters and to evaluate treatment success.

\section{Control}

Healthcare providers in the control group were instructed to provide care as usual to their patients, as described in the Dutch COPD healthcare guidelines. ${ }^{19} 20$ These guidelines are in line with guidelines from the European Respiratory Society, the American Thoracic Society ${ }^{4}$ and the GOLD ${ }^{3}$ guideline. The ABC scale and tool were not used in the control group.

\section{Measurements}

Health-related quality of life data were collected at four different points in time: at baseline and at 6-month, 12-month and 18-month follow-up. A set of questionnaires, that is, SGRQ, CAT and PACIC, was sent by the researchers and completed by patients at home without supervision, either on paper or online (as preferred by the patient). Patients received reminders if they had not returned the questionnaires within 3 weeks. 
The SGRQ ${ }^{2122}$ is a disease-specific measure of health status with scores ranging from 0 to 100 (=maximum impairment). Missing data were handled as described in the SGRQ Manual. ${ }^{23}$

The CAT is another disease-specific questionnaire with scores ranging from 0 to 40 , where higher scores indicate greater impairment of health-related quality of life. Scores were calculated if no more than two items were missing. ${ }^{15}$

The PACIC is a validated questionnaire that assesses patients' perceptions of the quality of care they have received in the past 6 months. Scores range from 1 to 5 , with higher scores representing higher perceived quality of care. ${ }^{16}$ As no specific missing data rules are provided for the PACIC, it was decided to only include patients in the analyses if at least $50 \%$ of the questions were completed. ${ }^{24}$

Objective parameters (ie, lung function and exacerbations) were entered by the healthcare providers into the registration system developed for this trial. Reminders to report the outcomes were sent twice during the 18-month follow-up.

\section{Outcomes}

The primary outcome measure was a clinically relevant improvement on the SGRQ ${ }^{14}$ defined as a decrease of at least four points on the total score of the SGRQ between baseline and the 18-month follow-up.

Secondary outcomes were as follows:

1. Clinically relevant improvement on the SGRQ between baseline and 6 months and between baseline and 12 months.

2. Clinically relevant deterioration on the SGRQ between baseline and 6 months, baseline and 12 months and baseline and 18 months.

3. SGRQ total score at 18 months.

4. CAT score at 18 months.

5. PACIC score at 12 months and at 18 months.

According to our research protocol, ${ }^{17}$ two other clinical outcomes were to be used, that is, lung function and exacerbation rate. Data for these analyses had to be reported by healthcare providers. However, in the control group, these data were reported for only one-third of the patients, a problem encountered because of the pragmatic design of the study. Owing to this large amount of missing data, it was decided not to address these two outcomes.

\section{Sample size}

The sample size calculation ${ }^{17}$ indicated that a total of 360 patients (180 patients per arm) were required to detect a difference in the response rate on the primary outcome between the intervention and control group (ie, $50 \%$ vs $30 \%$ patients with a clinically relevant improvement of at least four points in the intervention group and control group, respectively ${ }^{14}$ ), with an attrition rate of $25 \%$, a power of $80 \%$ to detect this difference and a two-tailed $\alpha$ of $5 \%$. We estimated that 40 GPs (average of 5 patients per GP) and 20 pulmonologists (average of 8 patients per pulmonologist) were required. A detailed description of the sample size calculation can be found in online supplementary appendix $\mathrm{B}$.

\section{Statistical analyses}

Data were analysed according to the intention-to-treat principle, that is, all available data of all randomised healthcare providers and patients were included in the analysis, using maximum likelihood inference with mixed regression for repeated measures. To address the primary outcome and the first two secondary outcomes (see above), change scores in the SGRQ were calculated by subtracting the baseline score from the scores at the 6-month, 12-month and 18-month follow-up. These change scores were then dichotomised into improved (ie, a decrease of four points or more on the SGRQ total score ${ }^{14}$ ) versus not improved, and into deteriorated (ie, an increase of four points or more on the SGRQ total score ${ }^{14}$ ) versus not deteriorated. The relationship between treatment and SGRQ improvement (yes or no) was then analysed with mixed logistic regression, taking into account that the times of measurement (change after 6,12 and 18 months) were nested within patients, and patients were nested within healthcare providers (three levels). Treatment arm (ie, intervention group vs control group), time, treatment by time interaction and covariates were incorporated into the model as predictors. Covariates included in the analyses were age, sex, smoking status at baseline and healthcare setting (ie, primary care vs hospital care). This analysis was repeated three times for the outcome clinically relevant SGRQ improvement yes/no, with 18 months (primary outcome) and 6 and 12 months (secondary outcomes) as reference time points, respectively, in order to estimate and test the treatment effect in a simple way for each time point (primary: 18 months, secondary: 6 and 12 months).

The same analyses were repeated for the outcome clinically relevant SGRQ deterioration yes/no.

To address the other secondary outcomes-the SGRQ total score, CAT total score and PACIC total scoreanalyses were performed with mixed linear regression, with cluster, patient and measurements as three levels. Predictors used in the model were time using dummy coding with baseline as the reference category, and dummy indicators for the 12-month and 18-month follow-up, and for SGRQ and CAT also a dummy indicator for the 6-month follow-up, treatment by time interaction and the same covariates as mentioned above. The interaction effect of treatment with the dummy indicator for 18 months represents the group difference in change from baseline to 18 months, and likewise for the other two treatment by time dummy interaction terms. Further, given that baseline is the reference time point, the treatment effect itself is the group difference at baseline $(0$ months), which can be expected to be zero due to the randomised treatment assignment. If this treatment effect was indeed not significant, then it was removed 
from the mixed model. The treatment by time interaction effect then became equivalent to the treatment effect at follow-up adjusted for the baseline as a covariate. ${ }^{25-27}$

The primary treatment effect and the effect on improvement after 6 and 12 months were tested using $\alpha=0.05$ (two-tailed) following the protocol. However, in view of multiple testing, treatment effects on the other secondary outcomes were required to be significant at $\alpha=0.01$. All analyses were performed using IBM SPSS Statistics for Windows, V.21.0.

\section{Sensitivity analyses}

For the purpose of sensitivity analysis for the primary outcome, a mixed logistic regression analysis was also performed on only those patients for whom an SGRQ score at baseline and at 18 months had been recorded, allowing computation of change without borrowing information from other patients or other points in time in case of a missing value at 18 months. Hence, patients were nested in clusters and the dependent variable was a dichotomous change score at 18 months (ie, improved vs not improved). The results of this analysis were compared with those of the intention-to-treat analysis including all available measurements of all patients.

\section{RESULTS}

A total of 62 healthcare providers were randomised into the two treatment groups: 42 from primary care and 20 from hospital care. Three healthcare providers from primary care and three from hospital care did not include any patients. Figure 2 shows the study flow chart with the number of healthcare providers and patients included in the study and randomised in the intervention or control group. In the intervention group, the average age of the healthcare providers was 50.4 years $(\mathrm{SD}=8.3)$ and in the control group it was 50.3 years $(\mathrm{SD}=7.5)$. The average number of years of work experience with patients with COPD in the intervention group was 15.1 years $(\mathrm{SD}=8.9)$ and in the control group it was 11.6 years $(\mathrm{SD}=7.5)$. In the intervention group and control group, the numbers of male healthcare providers were six and nine, respectively.

Thirteen patients dropped out before the baseline measurement and were excluded from the analyses. A total of 357 patients completed at least one set of questionnaires. At 18 months, 305 patients, from 56 clusters, completed the study (of these 305 patients, 11 patients did not complete the SGRQ at baseline).

The baseline characteristics of the 357 patients included in the intervention group and control group are shown in table 1. Patients from the intervention group showed a somewhat lower $\mathrm{FEV}_{1} / \mathrm{FVC}$ ratio, and $\mathrm{FEV}_{1 \%}$.

\section{Intervention compliance}

To check for intervention compliance, we looked at the number of times the ABC scale was completed, the number of times a treatment plan was made and the number of

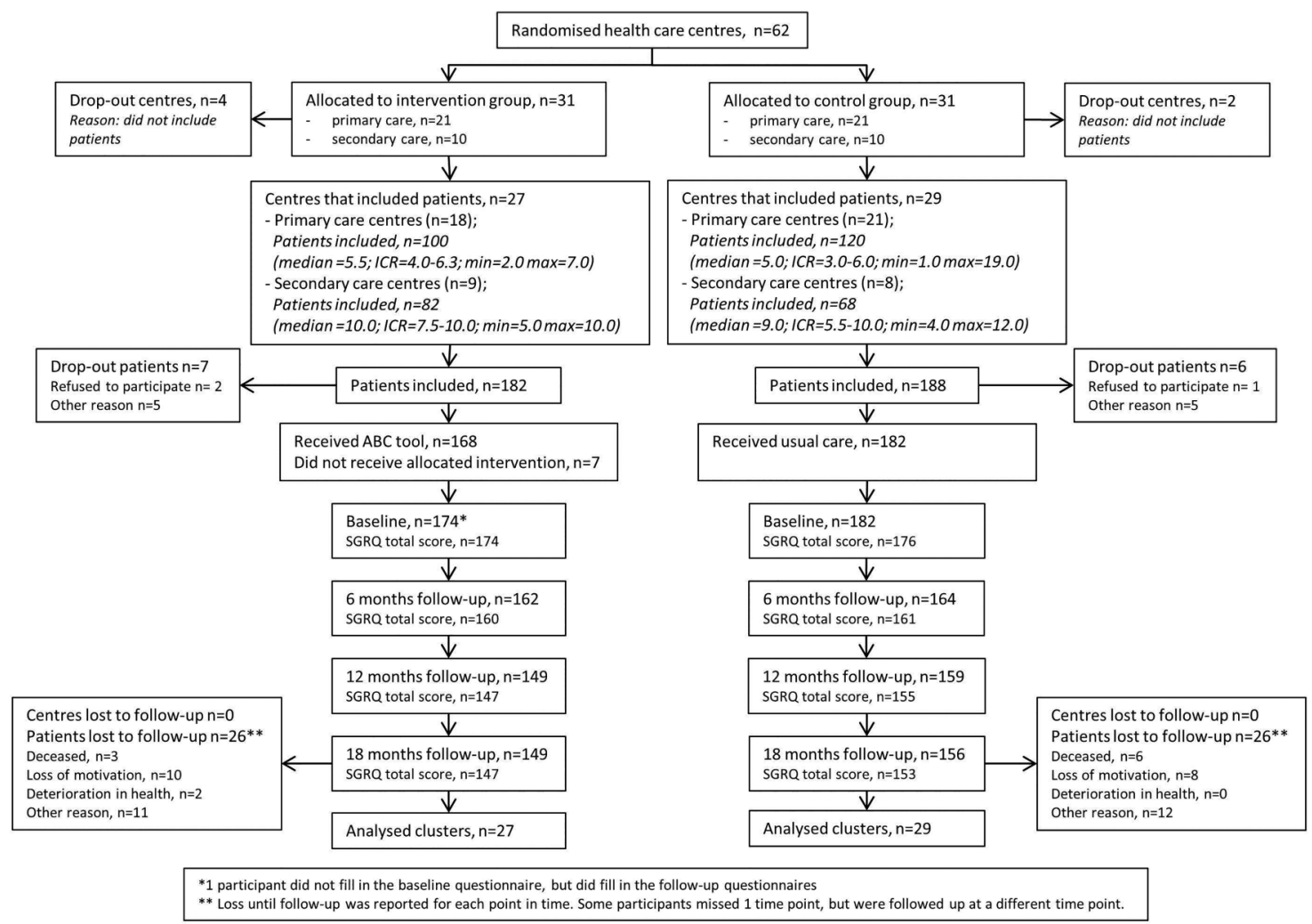

Figure 2 Flow chart of patients in the study. ABC tool, Assessment of Burden of COPD tool; ICR, interquartile range; SGRQ, St. George's Respiratory Questionnaire. 
Table 1 Patients' baseline characteristics

\begin{tabular}{|c|c|c|}
\hline & $\begin{array}{l}\text { Intervention } \\
\text { group } \\
(n=175)\end{array}$ & $\begin{array}{l}\text { Control } \\
\text { group } \\
(n=182)\end{array}$ \\
\hline Age, years, mean (SD) & $64.8(8.7)$ & $65.8(8.8)$ \\
\hline Sex, male, \% (n) & $52.6(92)$ & $60.4(110)$ \\
\hline \multicolumn{3}{|l|}{ Recruiting healthcare provider } \\
\hline Primary care, \% (n) & $54.9(96)$ & $63.7(116)$ \\
\hline Hospital care, \% (n) & $45.1(79)$ & $36.3(66)$ \\
\hline $\mathrm{FEV}_{1} / \mathrm{FVC}$ ratio, mean (SD) & $48.5(12.8)$ & $52.1(11.8)$ \\
\hline $\begin{array}{l}\mathrm{FEV}_{1}, \% \text { predicted, mean } \\
\text { (SD) }\end{array}$ & $56.6(17.8)$ & $62.3(19.8)$ \\
\hline \multicolumn{3}{|l|}{ GOLD stage, \% (n) } \\
\hline $1\left(\mathrm{FEV}_{1}>80 \%\right.$ predicted $)$ & $8.6(15)$ & $17.0(31)$ \\
\hline $2\left(\mathrm{FEV}_{1} 50-80 \%\right.$ predicted $)$ & $48.6(85)$ & $46.7(85)$ \\
\hline $3\left(\mathrm{FEV}_{1} 30-50 \%\right.$ predicted $)$ & $30.9(54)$ & $24.2(44)$ \\
\hline $4\left(\mathrm{FEV}_{1}<30 \%\right.$ predicted $)$ & $5.1(9)$ & $2.7(5)$ \\
\hline Missing & $6.9(12)$ & $9.3(17)$ \\
\hline \multicolumn{3}{|c|}{ Diagnosed with COPD since, \% (n) } \\
\hline 1-3 year(s) & $33.1(58)$ & $26.4(48)$ \\
\hline$>3$ years & $62.3(109)$ & $67.0(122)$ \\
\hline Unknown & $4.6(8)$ & $6.6(12)$ \\
\hline \multicolumn{3}{|c|}{ Number of exacerbations in last year, \% (n) } \\
\hline 0 & $44.0(77)$ & $49.5(90)$ \\
\hline 1 & $26.3(46)$ & $24.7(45)$ \\
\hline 2 & $12.0(21)$ & $10.4(19)$ \\
\hline$>2$ & $13.7(24)$ & $7.7(14)$ \\
\hline Missing & $4.0(7)$ & $7.7(14)$ \\
\hline \multicolumn{3}{|l|}{ Smoking status, \% (n) } \\
\hline Current smoker & $32.6(57)$ & $24.7(45)$ \\
\hline Ex-smoker & $60.0(105)$ & $60.4(110)$ \\
\hline Never smoked & $5.1(9)$ & $4.4(8)$ \\
\hline Missing & $2.3(4)$ & $10.4(19)$ \\
\hline $\begin{array}{l}\text { Pack-years smoking, mean } \\
\text { (SD) }\end{array}$ & $33.2(28.3)$ & $30.8(23.7)$ \\
\hline \multicolumn{3}{|l|}{ Baseline SGRQ, mean (SD) } \\
\hline Symptoms & $49.9(22.2)$ & $44.2(25.5)$ \\
\hline Activity & $44.6(23.8)$ & $41.4(24.3)$ \\
\hline Impact & $24.6(14.7)$ & $22.8(15.1)$ \\
\hline Total & $39.7(17.8)$ & $36.2(19.3)$ \\
\hline
\end{tabular}

times a personal goal was formulated per patient according to the registration system of the $\mathrm{ABC}$ tool (example in figure 1 and box 1). On average, in 18 months, patients completed the $\mathrm{ABC}$ scale 2.7 times $(\mathrm{SD}=1.3)$. Furthermore, on average, a treatment plan was recorded 2.4 times $(\mathrm{SD}=1.3)$, and a personal goal was formulated 2.3 times $(\mathrm{SD}=1.3)$.

\section{Primary outcome: improvement after 18 months}

In the intervention group, $49(33.6 \%)$ patients showed a clinically relevant improvement, as defined by an improvement of at least four points, on the SGRQ after 18 months, compared with $33(22.3 \%)$ patients in the control group. The adjusted odds of a clinically relevant improvement after 18 months was 1.85 times as high

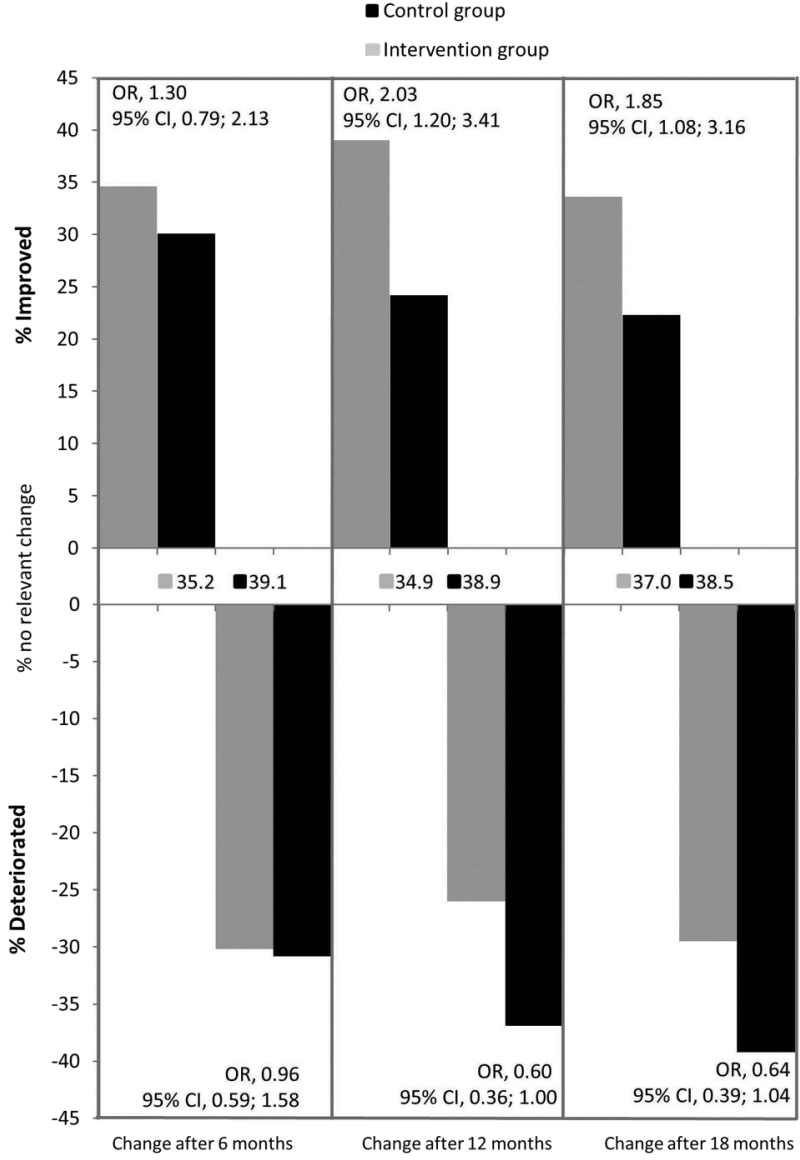

Figure 3 Comparison of clinically relevant improvement and deterioration on the SGRQ, after 6, 12 and 18 months between the intervention and control group, including percentages of patients at different time points with no clinically relevant change.

(95\% CI 1.08 to $3.16, p=0.02$ ) in the intervention group as in the control group (figure 3). The outcome variation between care providers was $0.035(\mathrm{p}=0.75)$, giving an intraclass correlation coefficient (ICC) of 0.01 according to the ICC definition for binary outcomes in Hedeker. ${ }^{28}$

As sensitivity analysis, a mixed logistic regression analysis was subsequently performed with the 294 cases with complete data on the SGRQ at baseline and after 18 months, disregarding the measurements after 6 and 12 months, so that clinical improvement was solely based on SGRQ at baseline and after 18 months, without borrowing information from other points in time or patients. This analysis yielded similar results as the previously mentioned mixed logistic, repeated-measures analysis of the primary analysis (adjusted OR 1.78, 95\% CI 1.02 to $3.10, \mathrm{p}=0.04$ ).

Furthermore, since there seemed to be an imbalance between groups at baseline with respect to $\mathrm{FEV}_{1 \%}$ and the $\mathrm{FEV}_{1} / \mathrm{FVC}$ ratio, we repeated the primary intentionto-treat analysis with $\mathrm{FEV}_{1 \%}$ predicted and $\mathrm{FEV}_{1} / \mathrm{FVC}$ ratio added to the model as covariates. This analysis also resulted in significantly higher odds of improvement for 
Table 2 Effect of treatment (ABC tool) on the total score and subdomains of the SGRQ at different points in time, as established with mixed linear regression correcting for age, gender, healthcare setting and smoking status, $n=334$

\begin{tabular}{|c|c|c|c|c|c|c|}
\hline & \multicolumn{2}{|c|}{ Observed score, mean (SD) } & \multirow[b]{2}{*}{$\boldsymbol{\beta}^{*}$} & \multicolumn{2}{|l|}{$95 \% \mathrm{Cl}$} & \multirow[b]{2}{*}{ p Value } \\
\hline & Intervention group & Control group & & Lower & Upper & \\
\hline \multicolumn{7}{|c|}{ SGRQ symptoms } \\
\hline 6 months & $48.81(22.83)$ & $43.15(26.19)$ & -0.83 & -3.95 & 2.30 & 0.602 \\
\hline 12 months & $44.65(21.58)$ & $45.63(26.27)$ & -5.50 & -8.92 & -2.07 & 0.002 \\
\hline 18 months & $46.16(23.69)$ & $45.33(26.46)$ & -4.52 & -8.15 & -0.89 & 0.015 \\
\hline \multicolumn{7}{|l|}{ SGRQ activity } \\
\hline 6 months & 45.35 (24.54) & $43.36(25.96)$ & -0.86 & -3.74 & 2.02 & 0.557 \\
\hline 12 months & $44.66(24.92)$ & $43.62(26.86)$ & -1.12 & -4.00 & 1.77 & 0.447 \\
\hline 18 months & $44.23(26.59)$ & $43.72(27.45)$ & -2.34 & -5.52 & 0.83 & 0.147 \\
\hline \multicolumn{7}{|l|}{ SGRQ impact } \\
\hline 6 months & $25.45(16.24)$ & $23.14(15.92)$ & 0.23 & -1.82 & 2.29 & 0.822 \\
\hline 12 months & $24.43(15.94)$ & $24.51(15.59)$ & -1.46 & -3.42 & 0.50 & 0.144 \\
\hline 18 months & $23.86(15.58)$ & $24.68(17.36)$ & -2.59 & -4.66 & -0.52 & 0.014 \\
\hline \multicolumn{7}{|c|}{ SGRQ total score } \\
\hline 6 months & $39.88(19.09)$ & 36.79 (20.29) & -0.90 & -2.85 & 1.05 & 0.365 \\
\hline 12 months & $37.91(18.33)$ & $38.10(20.80)$ & -2.96 & -4.99 & -0.93 & 0.004 \\
\hline 18 months & 38.39 (19.26) & 37.84 (21.92) & -3.08 & -5.36 & -0.80 & 0.008 \\
\hline $\begin{array}{l}{ }^{*} \beta=\text { mixed linear } \\
\text { negative chang } \\
\text { the treatment ef } \\
\text { present table in } \\
\text { ABC tool, Asse }\end{array}$ & $\begin{array}{l}\text { significance yes/no. } \\
\text { Burden of COPD to }\end{array}$ & $\begin{array}{l}\text { oint in time. } \beta<0 \\
\text { ased on the SGF } \\
\text { ant. Effects befo } \\
\text { St. George's Res }\end{array}$ & $\begin{array}{l}\text { a lower } \\
\text { ts in thi } \\
g \text { the tr } \\
\text { Questio }\end{array}$ & he int & $\begin{array}{l}\text { oup. } \\
\text { xed m }\end{array}$ & $\begin{array}{l}\text { res or } \\
\text { deleting } \\
\text { d with the }\end{array}$ \\
\hline
\end{tabular}

the intervention group (adjusted OR 1.90, 95\% CI 1.07 to $3.38, \mathrm{p}=0.03$ ).

\section{Secondary outcomes \\ Improvement in SGRQ}

After 6 months, there was no statistically significant difference between groups with respect to the proportion of patients with a clinically relevant improvement in SGRQ (adjusted OR=1.30, 95\% CI 0.79 to 2.13 , $\mathrm{p}=0.30$ ). After 12 months, the adjusted odds of a minimal clinically relevant improvement in SGRQ was 2.03 times as high $(95 \%$ CI 1.20 to $3.41, \mathrm{p}<0.01)$ in the intervention group as in the control group (see figure 3 ).

\section{Deterioration in SGRQ}

The adjusted OR of the outcome clinically relevant deterioration in SGRQ was 0.96 after 6 months (95\% CI 0.59 to $1.58, \mathrm{p}=0.87$ ). After 12 months, the adjusted odds of a deterioration in the intervention group was 0.60 times as small as in the control group (95\% CI 0.36 to $1.00, \mathrm{p}=0.04)$. After 18 months, the difference between the intervention group and the control group was in the same direction as the difference after 12 months (adjusted $\mathrm{OR}=0.64,95 \%$ CI 0.39 to $1.04, \mathrm{p}=0.07$; see figure 3).

\section{SGRQ (continuous score)}

Table 2 shows the difference between treatment arms with respect to SGRQ total score and domain scores at 6-month, 12-month and 18-month follow-up, based on the final mixed model, that is, after deleting the group effect at baseline, which was not significant $(\mathrm{p}=0.195$; for details, see the Statistical Analyses paragraph in the Methods section). There was no significant difference between treatment arms on the total score after 6 months ( -0.90 points: $95 \%$ CI -2.85 to $1.05, \mathrm{p}=0.37$ ), but there was a significant difference after 12 months $(-2.96$ points: $95 \%$ CI -4.99 to $-0.93, \mathrm{p}<0.01)$ and after 18 months $(-3.08$ points: $95 \%$ CI -5.36 to -0.80 , $\mathrm{p}<0.01)$. There was no outcome variation between healthcare providers, giving an ICC of 0.00 . These results indicate that treatment according to the $\mathrm{ABC}$ tool was associated with better quality of life. For completeness, we mention that the mixed regression analysis with the treatment effect at baseline still in the model gave very similar effect sizes and the same conclusions about the significance of each effect. Figure 4A shows the change of the observed means in SGRQ total score after 6-month, 12-month and 18-month follow-up compared with baseline measurement, for both groups. Since observed means can be biased due to dropout, figure 4B shows the change in predicted values based on the mixed regression model, which is much less prone to selection bias. The two plots showed almost the same pattern, that is, an increase in group difference in favour of intervention up to month 12 and maintenance of that difference till 18 months.

Additional analyses of the subdomains of the SGRQ showed that, after 18 months, the intervention group had a better score on the symptom domain $(-4.52$ points: $95 \%$ CI -8.15 to $-0.89, \mathrm{p}=0.015)$. However, this was just short of significance when taking the more 

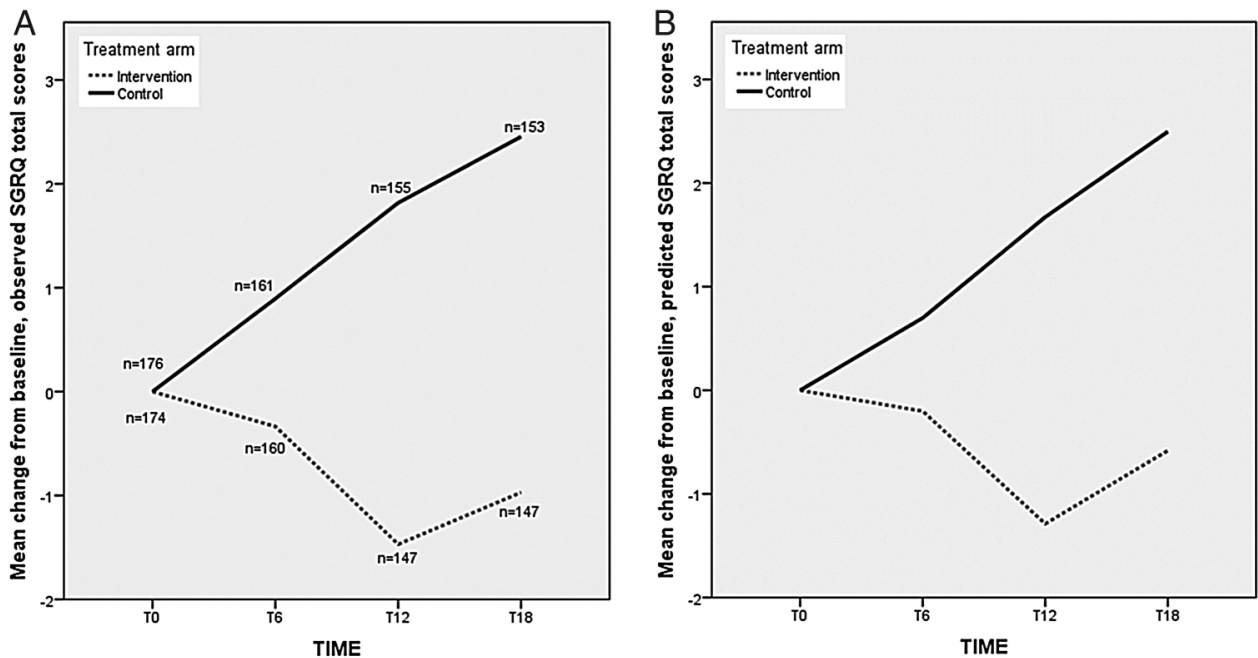

Figure 4 (A) Mean change in observed SGRQ total scores at 6-month, 12-month and 18-month follow-up compared with baseline, with a higher score indicating worse quality of life. (B) Mean change in predicted SGRQ total scores at 6-month, 12-month and 18-month follow-up compared with baseline, with a higher score indicating worse quality of life. SGRQ, St. George's Respiratory Questionnaire.

stringent significance level of $1 \%$ into account. There was a significant difference in favour of the intervention group on the subdomain impact $(-2.59$ points: $95 \%$ CI -4.66 to $-0.52, \mathrm{p}=0.01$ ), but not on the activity domain $(-2.34$ points: $95 \%$ CI -5.52 to $0.83, \mathrm{p}=0.15)$.

\section{COPD Assessment Test}

The total CAT scores of the treatment groups after 18 months did not differ significantly from each other $(-0.26$ points: $95 \%$ CI -1.52 to $0.99, p=0.68)$. There was no outcome variation between healthcare providers, thus yielding an ICC of 0.00 .

\section{Patient Assessment of Chronic Illness Care}

The analyses of the PACIC total score showed that treatment had a significant effect after 18 months on the total score of 0.32 points $(95 \%$ CI 0.14 to $0.50, \mathrm{p}<0.01$; see table 3$)$. The outcome variation between healthcare providers was $0.886(\mathrm{p}=0.08)$, yielding an ICC of 0.05 .

Analyses of the subdomains showed a significant difference between treatment arms at 18 months in all domains $(\mathrm{p}<0.01)$, except for the 'follow-up/coordination' domain (see table 3). These results indicate that treatment according to the $\mathrm{ABC}$ tool increased perceived quality of care as compared with the control group. Table 3 also displays the results after 12 months.

\section{DISCUSSION}

Main findings

We were able to analyse three different outcome measures related to disease-specific quality of life and perceived quality of care. We found significant differences between intervention and control arm on the SGRQ and the PACIC, but not on the CAT.

\section{St. George's Respiratory Questionnaire}

The use of the ABC tool in daily care resulted in more patients experiencing an improved disease-specific quality of life as measured by the SGRQ after a period of 18 months, compared with usual care. This result was also found after 12 months, but not after 6 months. The latter might be explained by the fact that the collaboration between patient and healthcare provider using the $\mathrm{ABC}$ tool requires time and experience to work optimally, and that interventions often also require a behavioural change of the patient. The additional analyses of the different domains of the SGRQ showed that there was mainly an improvement in the symptom domain and the impact domain, but these associations are just short of significance when taking the more stringent significance level of $1 \%$ into account to correct for multiple testing of secondary outcomes.

\section{COPD Assessment Test}

We expected to find results on the CAT comparable with the SGRQ since both questionnaires are strongly correlated $^{29-31}$ and in previous studies the CAT and the SGRQ usually showed similar results. ${ }^{32-34}$

Additionally, a systematic review about the CAT $^{29}$ found that the CAT is a reliable, valid and responsive instrument. Our study however did not indicate any differences between the treatment arms, which might relate to the fact that most studies evaluating the responsiveness of the CAT focused on patients with acute exacerbations and on patients receiving pulmonary rehabilitation interventions. ${ }^{35-38}$ In our study, the ABC tool was used in stable patients from primary and hospital care. This might indicate that the CAT, compared with the SGRQ, is less sensitive to change in more stable situations than the SGRQ. 
Table 3 Effect of treatment ( $\mathrm{ABC}$ tool) on the total score and subdomains of the PACIC at different points in time, as established with mixed linear regression correcting for age, gender, healthcare setting and smoking status, $n=331$

\begin{tabular}{|c|c|c|c|c|c|c|}
\hline & \multirow{2}{*}{$\begin{array}{l}\text { Score in intervention } \\
\text { group, mean (SD) }\end{array}$} & \multirow{2}{*}{$\begin{array}{l}\text { Score in control } \\
\text { group, mean (SD) }\end{array}$} & \multirow[b]{2}{*}{$\boldsymbol{\beta}^{\star}$} & \multicolumn{2}{|l|}{$95 \% \mathrm{Cl}$} & \multirow[b]{2}{*}{ p Value } \\
\hline & & & & Lower & Upper & \\
\hline \multicolumn{7}{|l|}{ Activation } \\
\hline 12 months & $3.26(1.26)$ & $2.97(1.22)$ & 0.15 & -0.11 & 0.41 & 0.267 \\
\hline 18 months & $3.45(1.21)$ & $2.90(1.24)$ & 0.39 & 0.14 & 0.65 & 0.003 \\
\hline \multicolumn{7}{|c|}{ Delivery system design } \\
\hline 12 months & $3.55(1.07)$ & $3.26(1.08)$ & 0.19 & -0.04 & 0.43 & 0.100 \\
\hline 18 months & $3.73(1.03)$ & $3.11(1.10)$ & 0.52 & 0.30 & 0.75 & $<0.001$ \\
\hline \multicolumn{7}{|l|}{ Goal setting } \\
\hline 12 months & $3.21(1.12)$ & $2.57(1.00)$ & 0.40 & 0.18 & 0.61 & $<0.001$ \\
\hline 18 months & $3.24(1.05)$ & $2.53(0.97)$ & 0.50 & 0.29 & 0.71 & $<0.001$ \\
\hline \multicolumn{7}{|c|}{ Problem-solving } \\
\hline 12 months & $3.26(1.18)$ & $2.88(1.16)$ & 0.22 & 0.02 & 0.46 & 0.068 \\
\hline 18 months & $3.29(1.22)$ & $2.76(1.14)$ & 0.38 & 0.14 & 0.62 & 0.002 \\
\hline \multicolumn{7}{|c|}{ Follow-up/coordination } \\
\hline 12 months & $2.29(1.13)$ & $2.05(0.99)$ & 0.12 & -0.07 & 0.31 & 0.215 \\
\hline 18 months & $2.29(1.09)$ & $2.14(1.08)$ & 0.04 & -0.16 & 0.23 & 0.708 \\
\hline \multicolumn{7}{|l|}{ Total score } \\
\hline 12 months & $3.09(1.00)$ & $2.71(0.91)$ & 0.20 & 0.02 & 0.38 & 0.032 \\
\hline 18 months & $3.11(0.95)$ & $2.62(0.97)$ & 0.32 & 0.14 & 0.50 & 0.001 \\
\hline
\end{tabular}

${ }^{*} \beta=$ mixed linear regression weight for treatment at that point in time. $\beta>0$ indicates a higher score in the intervention group. Higher scores or positive change scores indicate a higher perceived quality of care based on the PACIC. Effects in this table are based on the mixed model after deleting the treatment effect at baseline, which was never significant (see the Methods section). Effects before deleting the treatment effect were very similar and agreed with the present table in terms of significance yes/no.

ABC tool, Assessment of Burden of COPD tool; PACIC, Patient Assessment of Chronic Illness Care.

\section{Patient Assessment of Chronic Illness Care}

In evaluating the effect of the $\mathrm{ABC}$ tool on patients' perceived quality of care (using the PACIC), a significantly better response was found in the ABC-guided group compared with the control group. Positive effects on quality of care were perceived in patient activation, decision support, goal setting and problem-solving, which could be expected from the person-centred COPD approach with the $\mathrm{ABC}$ tool. When developing the $\mathrm{ABC}$ tool, the main goal was to make a tool that measures burden of COPD, and additionally visualises the integrated health status and provides a treatment algorithm. Furthermore, the tool had to provide room for writing down a treatment plan including a personal treatment goal. All of these components are considered to be important in order to involve the patient in the decisionmaking process and help them take control of the disease, eventually leading to improved self-management and a better quality of life. ${ }^{39-41}$

\section{This research in the context of other research}

In 2013, Agusti and MacNee advocated more personalised medicine for patients with COPD,${ }^{42}$ by suggesting that healthcare providers need a 'control panel' for the assessment and management of COPD. To our knowledge, apart from the ABC tool, only one other instrument has been developed for this purpose, ${ }^{43}$ although this tool has not yet been evaluated in a randomised trial.
In the management of COPD, interventions are necessary to reduce its burden and prevent its progression. ${ }^{44}$ Although no interventions like the ABC tool were found in literature ${ }^{9}$ many studies have been described evaluating the effect of behavioural interventions in patients with COPD on disease-specific quality of life. These studies show varying results due to different populations, methods and interventions. ${ }^{46-54}$ In many cases, no clinically relevant or statistically significant effect on the SGRQ was found.$^{50}{ }^{53-55}$ Interventions that did result in significant effects on the SGRQ were often much more demanding and intensive, such as pulmonary rehabilitation programmes, ${ }^{46} 47$ integrated disease management programmes, ${ }^{48}$ thorough proactive self-management education ${ }^{49}$ or weekly home visits by health professionals. ${ }^{50}$ The ABC tool however is a much more simple and easy-to-use visual approach that can be deployed as a communication tool in routine COPD care, facilitating shared decision-making. ${ }^{56-58}$

\section{Strengths and limitations}

A strength of the study was the fact that it was executed in almost every province of the Netherlands, in primary and hospital care, providing information about the effects of the intervention in different settings and disease severities. This has positive consequences for the generalisability of the results and potential implementation of the ABC tool. Usual care was based on national guidelines which are in line with international 
guidelines. However, different usual care in other countries cannot be excluded, which might affect the generalisability to some extent of our results towards other countries.

An additional strength was the pragmatic design to test the effectiveness of the $\mathrm{ABC}$ tool in real-life routine practice, which makes the results more applicable to daily primary and hospital care. However, the pragmatic approach also presented challenges. First, the use of the $\mathrm{ABC}$ tool was not actively promoted during the study, which meant that $4 \%$ of the patients did not receive the intervention. Second, healthcare providers were not actively stimulated to practice using the tool (if they requested the opportunity to practice, a dummy account was provided), since we believed using the tool would be self-explanatory. It is conceivable that with more training with the $\mathrm{ABC}$ tool, the effect might have been even greater, and more training might be warranted when implementing the tool with less motivated/experienced healthcare providers.

Owing to an error in data collection, smoking status was not recorded in all patients in the control group at baseline. However, at the 15-month and 18-month follow-up, smoking status was recorded and these data were used to impute the baseline status in patients with missing smoking status at baseline. To validate this imputed baseline smoking status, Cohen's Kappa measure of agreement was calculated between the observed and the imputed smoking status in patients with available baseline data. Kappa was 0.86 , indicating good agreement, and it was therefore concluded that missing smoking status at baseline could be replaced with data at the 15-month or 18-month follow-up.

Perhaps due to randomisation at cluster level instead of individual patient level, there was some imbalance between both groups at baseline. The intervention group showed a lower initial lung function. In order to detect any possible confounding from this imbalance, we repeated the primary analysis with $\mathrm{FEV}_{1 \%}$ predicted and forced expiratory ratio (FER) as covariates in the model. This analysis yielded similar results. Additionally, on the symptom domain of the SGRQ, the intervention group seemed to score worse at baseline. However, this difference was not significant and we corrected for this difference by calculating change scores. Therefore, we conclude that the results remain unchanged, despite these imbalances.

When calculating the required sample size, the expected proportions of patients improved were difficult to estimate, since little evidence was available on the effect of disease management interventions on diseasespecific quality of life as measured by the SGRQ. ${ }^{59}$ Therefore, the expected proportions of patients improved were solely based on results of previous drug trials. ${ }^{6061}$ The results from our trial showed that the proportion of patients improved by four points-our primary outcome-was $33.6 \%$ in the intervention group compared with $22.3 \%$ in the control group. Although this difference was smaller than estimated for the sample size calculation, it was a statistically significant difference. This is at least partly due to the fact that the actual dropout rate and the ICC (18\% and 0.01 , respectively) were lower than expected in the study planning stage (25\% and 0.05 , respectively). The smaller than expected difference in the proportion of patients improved ( $11.3 \%$ observed vs $20 \%$ expected) may partly be due to the fact that, instead of for example a single drug intervention, a high variety of interventions were possible in this trial, which might dilute the effect. Another possible explanation is the fact that the group COPD patients included in the study was a stable group with better quality of life and therefore lower baseline SGRQ total scores than in other studies, leaving less room for improvement. ${ }^{62-65}$

Furthermore, no blinding and allocation concealment was possible due to the nature of the intervention. However, the researchers performed the analyses on a blinded dataset and were therefore unaware of the coding of treatment arm until unanimous conclusions had been drawn about the results by all authors.

\section{Implications}

This study showed a promising development towards person-centred care. Visualisation of the integrated health status seems to be a valid contribution to efforts to place patients in the driver seat of care planning, together with their healthcare provider. Future research should focus on replication of this trial, in other settings and perhaps for other diseases as well, to investigate the underlying mechanisms of the effect of the ABC tool and especially the visually facilitated shared decision-making.

\section{CONCLUSION}

Our trial results indicate that the ABC tool has an added value for patients with COPD. Patients treated with the $\mathrm{ABC}$ tool were more likely to report clinically relevant improvement in quality of life, as measured by the SGRQ, compared with patients treated with usual care. Patients also perceived quality of care as better when the ABC tool was applied. Further research is necessary to replicate the results and further investigate the added value of the $A B C$ tool in different settings.

\footnotetext{
Author affiliations

${ }^{1}$ Department of Family Medicine, CAPHRI School for Public Health and Primary Care, Maastricht University, Maastricht, The Netherlands

${ }^{2}$ Institute of General Practice, Medical Faculty of the Heinrich-Heine-University Düsseldorf, Düsseldorf, Germany

${ }^{3}$ Department of Methodology \& Statistics, CAPHRI School for Public Health and Primary Care, Maastricht University, Maastricht, The Netherlands

${ }^{4}$ Department of Public Health and Primary Care, Leiden University Medical Centre, Leiden, The Netherlands

${ }^{5}$ Institute for Health Policy and Management/Institute for Medical Technology Assessment, Erasmus University Rotterdam, The Netherlands

${ }^{6}$ Department of Pulmonary Diseases, Groningen Research Institute for Asthma and COPD (GRIAC), University of Groningen, University Medical Centre Groningen, Groningen, The Netherlands
} 
${ }^{7}$ Department of General Practice, University of Groningen, University Medical Centre Groningen, Groningen, The Netherlands

${ }^{8}$ Foundation PICASSO for COPD, Alkmaar, The Netherlands

${ }^{9}$ Department of Pulmonary Diseases, Radboud University Medical Centre, Nijmegen, The Netherlands

${ }^{10}$ Lung Foundation Netherlands, Amersfoort, The Netherlands

${ }^{11}$ Huisartsencoöperatie PreventZorg, Bilthoven, The Netherlands

${ }^{12}$ Department of Pulmonology and SZT Centre of Excellence for Asthma \&

COPD, Sint Franciscus Vlietland Gasthuis, Rotterdam, The Netherlands

Acknowledgements The $A B C$ tool was developed under the auspices of the Lung Alliance Netherlands (LAN) and prepared by an expert team installed by the LAN. The initiative for the development of the instrument was taken by the PICASSO foundation for COPD. The authors would like to thank Denise Schuiten, who was a valuable member of the expert team. They would also like to thank all healthcare providers (see online supplementary material file) and patients who participated in this study.

Contributors AHMS, NHC, MPMHR-vM, HAMK, TvdM, GMA, PNRD, SH, PLS, JCCMitV and OCPVS conceived and designed this study, and developed the ABC tool. AHMS and MT gathered the data. AHMS, DK, OCPvS and MT analysed and interpreted the data. GVB and LMAG provided statistical expertise on this paper and analysed and interpreted the data. AHMS drafted the manuscript. DK, OCPvS, JCCMitV, GvB and NHC advised on the preparation of the manuscript. All authors read, edited and approved the final version of the manuscript. All authors had full access to all of the data in the study and take responsibility for the integrity of the data and the accuracy of the data analysis.

Funding This paper presents independent research funded by the Lung Alliance Netherlands (http://www.longalliantie.nl). The funding agency had no influence on the design of the study, the analysis or the writing of the paper. The views expressed in this presentation are those of the authors and not necessarily those of the sponsor.

Competing interests All authors have completed the Unified Competing Interest form at http://www.icmje.org/coi_disclosure.pdf (available on request from the corresponding author), and AHMS, DK, MT, SH, PLS, GvB, MPMHR-vM, LMAG, NHC, TvdM, GMA, PNRD and JCCMitV declare that they have not had relationships with any company that might have an interest in the submitted work in the previous 3 years and no non-financial interests that may be relevant to the submitted work. HAMK's institution has received grants and fees for consultancies from Boehringer Ingelheim, Pfizer, Almirall, AstraZeneca, Chiesi, GlaxoSmithKline, Novartis and Takeda, all not related to this submitted work. OCPvS received personal and institutional grants of Pfizer and Boehringer Ingelheim, not related to this submitted work.

Ethics approval Medical Ethics Committee of Zuyderland Hospital, Heerlen, the Netherlands.

Provenance and peer review Not commissioned; externally peer reviewed.

Data sharing statement Authors are planning on producing further publications using this dataset. Afterwards, patient-level data and full dataset will be available from the corresponding author. Consent for sharing was not obtained from patients, but the presented data are anonymised and risk of identification is low.

Open Access This is an Open Access article distributed in accordance with the Creative Commons Attribution Non Commercial (CC BY-NC 4.0) license, which permits others to distribute, remix, adapt, build upon this work noncommercially, and license their derivative works on different terms, provided the original work is properly cited and the use is non-commercial. See: http:// creativecommons.org/licenses/by-nc/4.0/

\section{REFERENCES}

1. Mannino DM, Homa DM, Akinbami LJ, et al. Chronic obstructive pulmonary disease surveillance-United States, 1971-2000. MMWR Surveill Summ 2002:51:1-16.

2. Feenstra TL, van Genugten ML, Hoogenveen RT, et al. The impact of aging and smoking on the future burden of chronic obstructive pulmonary disease: a model analysis in the Netherlands. Am J Respir Crit Care Med 2001;164:590-6.
3. From the Global Strategy for Diagnosis, Management and Prevention of COPD, Global Initiative for Chronic Obstructive Lung Disease (GOLD) 2014. Secondary From the Global Strategy for Diagnosis, Management and Prevention of COPD, Global Initiative for Chronic Obstructive Lung Disease (GOLD) 2014. http://www. goldcopd.org/

4. Celli BR, MacNee W. Standards for the diagnosis and treatment of patients with COPD: a summary of the ATS/ERS position paper. Eur Respir J 2004;23:932-46.

5. Gruffydd-Jones K. A national strategy for the management of chronic obstructive pulmonary disease (COPD) in England: aiming to improve the quality of care for patients. Prim Care Respir J 2008;17 (Suppl 1):S1-8

6. Seemungal TA, Donaldson GC, Paul EA, et al. Effect of exacerbation on quality of life in patients with chronic obstructive pulmonary disease. Am J Respir Crit Care Med 1998;157: 1418-22.

7. Miravitlles M, Ferrer M, Pont A, et al. Effect of exacerbations on quality of life in patients with chronic obstructive pulmonary disease: a 2 year follow up study. Thorax 2004;59:387-95.

8. Miravitlles M, Molina J, Naberan $\mathrm{K}$, et al. Factors determining the quality of life of patients with COPD in primary care. Ther Adv Respir Dis 2007;1:85-92.

9. Slok AHM, In 't Veen JCCM, Chavannes $\mathrm{NH}$, et al. Development of the Assessment of Burden of COPD tool: an integrated tool to measure the burden of COPD. NPJ Prim Care Respir Med 2014;24: 14021

10. van der Molen T, Willemse BW, Schokker S, et al. Development, validity and responsiveness of the Clinical COPD Questionnaire. Health Qual Life Outcomes 2003;1:13.

11. Slok AHM, Bemelmans TCH, Kotz D, et al. The Assessment of Burden of COPD (ABC) scale: a reliable and valid questionnaire. COPD 2016 [epub ahead of print].

12. Bourbeau J, Nault D, Dang-Tan T. Self-management and behaviour modification in COPD. Patient Educ Couns 2004;52:271-7.

13. Hill K, Vogiatzis I, Burtin C. The importance of components of pulmonary rehabilitation, other than exercise training, in COPD. Eur Respir Rev 2013;22:405-13.

14. Jones PW. St. George's Respiratory Questionnaire: MCID. Copd 2005;2:75-9.

15. Jones PW, Harding G, Berry P, et al. Development and first validation of the COPD Assessment Test. Eur Respir $J$ 2009;34:648-54.

16. Glasgow RE, Wagner EH, Schaefer J, et al. Development and validation of the Patient Assessment of Chronic Illness Care (PACIC). Med Care 2005;43:436-44.

17. Slok AHM, In 't Veen JCCM, Chavannes NH, et al. Effectiveness of the Assessment of Burden of Chronic Obstructive Pulmonary Disease $(A B C)$ tool: study protocol of a cluster randomised trial in primary and secondary care. BMC Pulm Med 2014;14:131.

18. Bestall JC, Paul EA, Garrod R, et al. Usefulness of the Medical Research Council (MRC) dyspnoea scale as a measure of disability in patients with chronic obstructive pulmonary disease. Thorax 1999;54:581-6.

19. Long Alliantie Nederland. Zorgstandaard COPD. Amersfoort: Long Alliantie Nederland, 2010.

20. Smeele IJM, Van Weel C, Van Schayck CP, et al. NHG-Standaard COPD [Dutch national guideline COPD in primary care]. Huisarts Wet 2007;50:362-79.

21. Jones PW, Quirk FH, Baveystock CM. The St George's Respiratory Questionnaire. Respir Med 1991;85(Suppl B):25-31; discussion 33-7.

22. Jones PW, Quirk FH, Baveystock CM, et al. A self-complete measure of health status for chronic airflow limitation. The St. George's Respiratory Questionnaire. Am Rev Respir Dis 1992;145:1321-7.

23. Jones PW, Forde Y. St George's respiratory questionnaire manual. 2.3 ed. London: St. George's University of London, 2009.

24. Smidth M, Olesen F, Fenger-Grøn M, et al. Patient-experienced effect of an active implementation of a disease management programme for COPD—a randomised trial. BMC Fam Pract 2013;14:147.

25. Laird NM, Wang F. Estimating rates of change in randomized clinical trials. Control Clin Trials 1990;11:405-19.

26. Liu GF, Lu K, Mogg R, et al. Should baseline be a covariate or dependent variable in analyses of change from baseline in clinical trials? Stat Med 2009;28:2509-30.

27. van Breukelen GJ. ANCOVA Versus CHANGE From Baseline in Nonrandomized Studies: the difference. Multivariate Behav Res 2013;48:895-922.

28. Hedeker D. A mixed-effects multinomial logistic regression model. Stat Med 2003;22:1433-46. 
29. Gupta N, Pinto LM, Morogan A, et al. The COPD assessment test: a systematic review. Eur Respir J 2014;44:873-84.

30. Tsiligianni IG, van der Molen T, Moraitaki D, et al. Assessing health status in COPD. A head-to-head comparison between the COPD assessment test (CAT) and the clinical COPD questionnaire (CCQ). BMC Pulm Med 2012;12:20.

31. Sarioglu N, Hismiogullari AA, Bilen $\mathrm{C}$, et al. Is the COPD assessment test (CAT) effective in demonstrating the systemic inflammation and other components in COPD? Rev Port Pneumol (2006) 2016;22:11-17

32. Siler TM, Kerwin E, Singletary K, et al. Efficacy and Safety of Umeclidinium Added to Fluticasone Propionate/Salmeterol in Patients with COPD: results of Two Randomized, Double-Blind Studies. Copd 2016;13:1-10.

33. Mendoza L, Horta P, Espinoza J, et al. Pedometers to enhance physical activity in COPD: a randomised controlled trial. Eur Respir $J$ 2015;45:347-54.

34. Ghobadi H, Lari SM, Pourfarzi F, et al. The effects of atorvastatin on mustard-gas-exposed patients with chronic obstructive pulmonary disease: A randomized controlled trial. J Res Med Sci 2014:19:99-105.

35. Dodd JW, Hogg L, Nolan J, et al. The COPD assessment test (CAT): response to pulmonary rehabilitation. A multicentre, prospective study. Thorax 2011;66:425-9.

36. Jones PW, Harding G, Wiklund I, et al. Tests of the responsiveness of the COPD assessment test following acute exacerbation and pulmonary rehabilitation. Chest 2012;142:134-40.

37. Dodd JW, Marns PL, Clark AL, et al. The COPD Assessment Test (CAT): short- and medium-term response to pulmonary rehabilitation. Copd 2012;9:390-4.

38. Kon SS, Clark AL, Dilaver D, et al. Response of the COPD Assessment Test to pulmonary rehabilitation in unselected chronic respiratory disease. Respirology 2013;18:974-7.

39. Joosten EA, DeFuentes-Merillas L, de Weert GH, et al. Systematic review of the effects of shared decision-making on patient satisfaction, treatment adherence and health status. Psychother Psychosom 2008;77:219-26.

40. Bodenheimer T, Wagner EH, Grumbach K. Improving primary care for patients with chronic illness: the chronic care model, Part 2. JAMA 2002;288:1909-14.

41. Cicutto L, Brooks D, Henderson K. Self-care issues from the perspective of individuals with chronic obstructive pulmonary disease. Patient Educ Couns 2004;55:168-76.

42. Agusti A, Macnee W. The COPD control panel: towards personalised medicine in COPD. Thorax 2013;68:687-90.

43. Peters JB, Daudey L, Heijdra YF, et al. Development of a battery of instruments for detailed measurement of health status in patients with COPD in routine care: the Nijmegen Clinical Screening Instrument. Qual Life Res 2009;18:901-12.

44. Coultas D, Frederick J, Barnett B, et al. A randomized trial of two types of nurse-assisted home care for patients with COPD. Chest 2005;128:2017-24.

45. Oga T, Tsukino M, Hajiro T, et al. Analysis of longitudinal changes in dyspnea of patients with chronic obstructive pulmonary disease: an observational study. Respir Res 2012;13:85.

46. van Wetering CR, Hoogendoorn M, Mol SJ, et al. Short- and long-term efficacy of a community-based COPD management programme in less advanced COPD: a randomised controlled trial. Thorax 2010;65:7-13.

47. Boxall AM, Barclay L, Sayers A, et al. Managing chronic obstructive pulmonary disease in the community. A randomized controlled trial of home-based pulmonary rehabilitation for elderly housebound patients. J Cardiopulm Rehabil 2005;25:378-85.

48. Chavannes NH, Grijsen M, van den Akker M, et al. Integrated disease management improves one-year quality of life in primary care COPD patients: a controlled clinical trial. Prim Care Respir J 2009;18:171-6.

49. Koff PB, Jones RH, Cashman JM, et al. Proactive integrated care improves quality of life in patients with COPD. Eur Respir $J$ 2009;33:1031-8.

50. Bourbeau J, Julien M, Maltais F, et al, Chronic Obstructive Pulmonary Disease axis of the Respiratory Network Fonds de la Recherche en Santé du Québec. Reduction of hospital utilization in patients with chronic obstructive pulmonary disease: a disease-specific self-management intervention. Arch Intern Med 2003;163:585-91.

51. Monninkhof $\mathrm{E}$, van der Valk $\mathrm{P}$, van der Palen $\mathrm{J}$, et al. Effects of a comprehensive self-management programme in patients with chronic obstructive pulmonary disease. Eur Respir $J$ 2003;22:815-20.

52. Kruis AL, Boland MR, Assendelft WJ, et al. Effectiveness of integrated disease management for primary care chronic obstructive pulmonary disease patients: results of cluster randomised trial. BMJ 2014;349:95392.

53. Zwerink M, Brusse-Keizer M, van der Valk PD, et al. Self management for patients with chronic obstructive pulmonary disease. Cochrane Database Syst Rev 2014;(3):CD002990.

54. Hermiz O, Comino E, Marks G, et al. Randomised controlled trial of home based care of patients with chronic obstructive pulmonary disease. BMJ 2002;325:938.

55. Kruis AL, Smidt N, Assendelft WJ, et al. Integrated disease management interventions for patients with chronic obstructive pulmonary disease. Cochrane Database Syst Rev 2013;(10): CD009437.

56. Oliver SM. Living with failing lungs: the doctor-patient relationship. Fam Pract 2001;18:430-9.

57. Makoul G, Clayman ML. An integrative model of shared decision making in medical encounters. Patient Educ Couns 2006;60:301-12.

58. Elwyn G, Frosch D, Thomson R, et al. Shared decision making: a model for clinical practice. J Gen Intern Med 2012;27:1361-7.

59. Lemmens KM, Nieboer AP, Huijsman R. A systematic review of integrated use of disease-management interventions in asthma and COPD. Respir Med 2009;103:670-91.

60. Tashkin D, Kesten S. Long-term treatment benefits with tiotropium in COPD patients with and without short-term bronchodilator responses. Chest 2003;123:1441-9.

61. Casaburi R, Mahler DA, Jones PW, et al. A long-term evaluation of once-daily inhaled tiotropium in chronic obstructive pulmonary disease. Eur Respir J 2002;19:217-24.

62. Rutten-van Mölken M, Roos B, Van Noord JA. An empirical comparison of the St George's Respiratory Questionnaire (SGRQ) and the Chronic Respiratory Disease Questionnaire (CRQ) in a clinical trial setting. Thorax 1999;54:995-1003.

63. Tashkin DP, Celli B, Senn S, et al. A 4-year trial of tiotropium in chronic obstructive pulmonary disease. $N$ Engl J Med 2008;359:1543-54

64. Spencer S, Calverley PM, Sherwood Burge P, et al. Health status deterioration in patients with chronic obstructive pulmonary disease. Am J Respir Crit Care Med 2001;163:122-8.

65. Jones PW, Bosh TK. Quality of life changes in COPD patients treated with salmeterol. Am J Respir Crit Care Med $1997 ; 155: 1283-9$. 